\title{
Investigation of Electronic Structure, Optical Properties, Molecular Electrostatic Potential maps (EPM) and Aquatic toxicity of HfO2, $\mathrm{HfO} .88 \mathrm{SiO} .12 \mathrm{O} 2$, Hf0.88Ge0.12O2 and $\mathrm{HfO} .88 \mathrm{SnO} 0.1202$ by computational methods
}

\section{Unesco Chakma}

European University of Bangladesh

Ajoy Kumer ( $\sim$ kumarajoy.cu@gmail.com )

Bangladesh University of Engineering and Technology https://orcid.org/0000-0001-5136-6166

Tomal Hossain

European University of Bangladesh

Md. Sayed Hossain

Bangladesh Atomic Energy Commission

Md. Monsur Alam

European University of Bangladesh

Md. Shariful Islam

European University of Bangladesh

Rubel Shaikh

European University of Bangladesh

Ismat Jahan jony

European University of Bangladesh

Jahedul Islam

Presidency University

\section{Research Article}

Keywords: Band gap, DOS, Optical properties, Dielectric Function, Doping Electrostatic Potential Map (EPM), Aquatic Toxicity and DFT

Posted Date: February 15th, 2022

DOI: https://doi.org/10.21203/rs.3.rs-1260775/v1

License: @ (i) This work is licensed under a Creative Commons Attribution 4.0 International License. Read Full License 


\section{Abstract}

This research work conveys the computationally investigation of Hafnium (IV) oxide and its doped crystals by Si, Ge and $\mathrm{Sn}$ atom replacing on the oxygen atom in $\mathrm{HfO}_{2}$. As Hafnium (IV) oxide has been used in power-electronics devices of MOSFETs and electronics as RRAM due to wide band gap which makes a vast problems creating high resistance. Regarding this case, the Hafnium (IV) oxide has selected and inputs how the band gap has reduced after doping the large surface area of atoms, such as Si, Ge and Sn. The lattice parameters and bandgaps were calculated with the Perdew-Burke-Ernzerhof (PBE), Revised Perdew-Burke-Ernzerhof (RPBE), Perdew Wang (PW91), Wu-Cohen (WC), and Perdew-BurkeErnzerhof for solids (PBEsol) non-local functionals of the generalized gradient approximations (GAA). The Perdew-Burke-Ernzerhof (PBE) functional provided better result which is similar to the reference value of mother crystal, $\mathrm{HfO}_{2}$. This first principle method in view of density functional theory (DFT) focuses the structural geometry, electronic structure and optical properties employing conventional calculations pertaining to $\mathrm{HfO}_{2}$ executing the computational tools of the CASTAP code from material studio 8.0. The band gap was recorded by $4.340 \mathrm{eV}, 2.033 \mathrm{eV}, 1.686 \mathrm{eV}$ and $3.210 \mathrm{eV}$ for $\mathrm{HfO}_{2}$, $\mathrm{Hf}_{0.88} \mathrm{Si}_{0.12} \mathrm{O}_{2} \mathrm{Hf}_{0.88} \mathrm{Ge}_{0.12} \mathrm{O}_{2}$ and $\mathrm{Hf}_{0.88} \mathrm{Sn}_{0.12} \mathrm{O}_{2}$ crystals through the Generalized Gradient Approximation (GGA) with Perdew Burke Ernzerhof (PBE). Secondly, it had also justified doing further investigations by GGA with RPBE, GGA with PW91, GGA with WC and GGA with $\mathrm{PBE}_{\mathrm{SOL}}$, the band gap for $\mathrm{HfO}_{2}, \mathrm{Hf}_{0.88} \mathrm{Si}_{0.12} \mathrm{O}_{2}, \mathrm{Hf}_{0.88} \mathrm{Ge}_{0.12} \mathrm{O}_{2}$ and $\mathrm{Hf}_{0.88} \mathrm{Sn}_{0.12} \mathrm{O}_{2}$ were at $4.427 \mathrm{eV}, 2.093 \mathrm{eV}, 1.744 \mathrm{eV}$, and 3.262 $\mathrm{eV}$, respectively using GGA with WC, $4.333 \mathrm{eV}, 2.032 \mathrm{eV}, 1.675 \mathrm{eV}$ and $3.172 \mathrm{eV}$, respectively using GGA with PW91, 4.252 eV, $2.002 \mathrm{eV}$, $1.632 \mathrm{eV}$ and $3.086 \mathrm{eV}$, respectively using GGA with WC $4.245 \mathrm{eV}, 2.001 \mathrm{eV}, 1.629 \mathrm{eV}$, and $3.076 \mathrm{eV}$, respectively using GGA with PBE $\mathrm{SOL}_{\text {. }}$ Moreover the DFT and PDOS were simulated for evaluating the nature of $6 s^{2}, 5 p^{6}, 4 f^{14}, 5 d^{2}$ orbital for a Hf atom, $3 s^{2}, 2 p^{6}$ orbital for Si atom, and $4 s^{2}, 3 p^{6}, 3 d^{10}$ orbital for $\mathrm{Ge}$ atom, $4 d^{10}, 5 s^{2}, 5 p^{2}$ for $\mathrm{Sn}$ atom and $2 \mathrm{~s}$ and $2 p$ orbital for $\mathrm{O}$ atom of $\mathrm{Hf}_{0.88} \mathrm{Ge}_{0.12} \mathrm{O}_{2}$ and $\mathrm{Hf}_{0.88} \mathrm{Sn}_{0.12} \mathrm{O}_{2}$ crystals. The optical properties, for instance, absorption, reflection, refractive index, conductivity, dielectric function, loss function, electrostatic potential map and aquatic toxicity were calculated.

\subsection{Introduction}

In the technological era, there are many challenges raised due to development of MOSFETs for amplification the signals or voltages in current electronics devices even future generation devices having the principle of the semiconductor [1, 2]. In addition, MOSFETs consists of body, source, gate and drain, but many critical and immediate stumbling blocks are obtained during the optimization of the gate stack $[3,4]$. As a result, the cardinal function of MOSFETs is not working in the proper way. Specifically, when MOSFETs is composed by $\mathrm{HfO}_{2}$, is able to perform the much larger memory windows even no degradation of memory [5-7]. The main cause is to stay a high coercive field $(1-2 \mathrm{MV} / \mathrm{cm})$. In this case, the interfaces of $\mathrm{HfO}_{2}$ is related with the Fermi energy level to control and amplify the electric signal or voltage from minimum conduction band (MCB) or maximum valence band (MVB) in devices, and metals body is the driving chair to operate the full procedure. Having some good user friendly properties of $\mathrm{HfO}_{2}$, there are some drawbacks, such as crystalline life time, wide band gap, Low-frequency noise [8], $\gamma$-ray irradiation influence [9], lattice parameter [10], and gate dielectric function[11, 12]. As a result, in the principle of interface overlapping, the Si and non-Si substrates (e.g., Ge, and Sn) are added as doping to determine their opto-electronic properties developing the useable capacity in RRAM, ferromagnetic devices $[2,13]$, the dielectric thin films [14], band-edge CMOS applications [15].

This manuscript has organized as follows $\mathrm{HfO}_{2}, \mathrm{Hf}_{0.88} \mathrm{Si}_{0.12} \mathrm{O}_{2} \mathrm{Hf}_{0.88} \mathrm{Ge}_{0.12} \mathrm{O}_{2}$ and $\mathrm{Hf}_{0.88} \mathrm{Sn}_{0.12} \mathrm{O}_{2}$ crystals including the electronic structure, density of states and optical properties. In this case, the GGA with PBE functional has used due to its most accuracy and acceptance for heavy metals containing crystals [16-22] with the comparing other five GGA functionals.

Doping has widely been utilized and demonstrated as an effective way to improve the performance of oxide materials. Therefore, in order to improve the uniformity of the devices, a controllable resistive mechanism of the doped-oxide should be established. In this study, the influence of $\mathrm{Si}, \mathrm{Ge}$ and $\mathrm{Sn}$ doping on the MOSFETs, resistive random access memory (RRAM) characteristics of $\mathrm{HfO}_{2}$-based MOSFETs and RRAM device has been illustrated. In addition, the first principle method has been performed to analyze the electronic structure, density of states and optical properties $\mathrm{HfO}_{2}, \mathrm{Hf}_{0.88} \mathrm{Si}_{0.12} \mathrm{O}_{2} \mathrm{Hf}_{0.88} \mathrm{Ge}_{0.12} \mathrm{O}_{2}$ and $\mathrm{Hf}_{0.88} \mathrm{Sn}_{0.12} \mathrm{O}_{2}$ crystals. To calculate the comparative reflectivity, absorption and dielectric function among $\mathrm{HfO}_{2}, \mathrm{Hf}_{0.88} \mathrm{Si}_{0.12} \mathrm{O}_{2} \mathrm{Hf}_{0.88} \mathrm{Ge}_{0.12} \mathrm{O}_{2}$ and $\mathrm{Hf}_{0.88} \mathrm{Sn}_{0.12} \mathrm{O}_{2}$, the GGA with PBE functional has used because of its accuracy $[18,23]$.

Finally, from the perspective of our globe, especially the 3rd world countries like Bangladesh, is going to face the 4th industrial revolution in both the industries and advance electronics material sectors, where adequate MOSFETs, resistive random access memory 
(RRAM) characteristics of $\mathrm{HfO}_{2}$-based MOSFETs and RRAM device resources and development will be necessitated, otherwise, the revolutions will be hindered due to energy and lost the achievement for the goal of next development. To solve the upcoming difficulties with advanced electronics material, the $\mathrm{HfO}_{2}, \mathrm{Hf}_{0.88} \mathrm{Si}_{0.12} \mathrm{O}_{2} \mathrm{Hf}_{0.88} \mathrm{Ge}_{0.12} \mathrm{O}_{2}$ and $\mathrm{Hf}_{0.88} \mathrm{Sn}_{0.12} \mathrm{O}_{2}$ crystals could be one of the promising solutions in view of scientific evidence with commercial feasibilities.

\subsection{Computational Methods}

The first principle calculations were performed by the plane-wave basis with the pseudopotential methods in the framework of DFT, as implemented in the CASTEP code [24, 25]. We used five different non-local functionals, such as generalized gradient approximations (GGA) [26]: Perdew-Burke-Ernzerhof (PBE) [27], Revised Perdew-Burke-Ernzerhof (RPBE) [28], Perdew Wang (PW91), Wu-Cohen (WC) and Perdew-Burke-Ernzerhof for solids (PBEsol). Each exchange-correlation (XC) functional was computed using two different kineticenergy cut-offs: $500 \mathrm{eV}$ at norm conserving pseudo potentials, respectively. $2 \times 2 \times 2$ Monkhorst-Pack grid was used. The self-consistent field (SCF) tolerance was $1.0 \times 10^{-6}(\mathrm{eV} /$ atom). The total energy tolerance, maximum ionic Hellmann-Feynman force, and maximum ionic displacement tolerance were $2.0 \times 10^{-6}\left(\mathrm{eV} /\right.$ atom), $0.006(\mathrm{eV} / \AA)$ and $2.0 \times 10^{-6}(\AA)$, respectively. For the optical spectra calculations, a dense mesh of uniformly distributed k-points is required; hence, the Brillouin zone integration was performed using a $2 \times 4 \times 2$ grid of Monkhorst-Pack points. Next, the optical features, such as refractive index, reflectivity, absorption, conductivity and loss function, were similarly simulated for the calculation of the electronic structure and optical properties for the comparative study of band gaps for $\mathrm{HfO}_{2}, \mathrm{Hf}_{0.88} \mathrm{Si}_{0.12} \mathrm{O}_{2} \mathrm{Hf}_{0.88} \mathrm{Ge}_{0.12} \mathrm{O}_{2}$ and $\mathrm{Hf}_{0.88} \mathrm{Sn}_{0.12} \mathrm{O}_{2}$.

\subsection{Results And Discussions}

\subsection{Geometry of optimized structure}

The lattice parameter values of $\mathrm{HfO}_{2}, \mathrm{Hf}_{0.88} \mathrm{Si}_{0.12} \mathrm{O}_{2}, \mathrm{Hf}_{0.88} \mathrm{Ge}_{0.12} \mathrm{O}_{2}$ and $\mathrm{Hf}_{0.88} \mathrm{Sn}_{0.12} \mathrm{O}_{2}$ are calculated from the materials studio after optimizing their crystal structure which is listed in the Table 1. Withal, it must be noted for optimization structure showing in figure 1 (a) to 1(d) which was taken after simulation GGA with PBE, and has been considered as the standard functional of DFT having heavy metal atoms in crystal $[18,23,29]$

Table 1

Structural calculation by GGA with PBE

\begin{tabular}{|llllllllll|}
\hline Crystals & $\mathbf{a}$ & $\mathbf{b}$ & $\mathbf{c}$ & $\boldsymbol{\alpha}$ & $\boldsymbol{\beta}$ & $\boldsymbol{\gamma}$ & Crystal type & Space group & Density $\mathbf{g} / \mathbf{c m}^{\mathbf{3}}$ \\
\hline $\mathrm{HfO}_{2}$ & 5.040 & 5.074 & 5.269 & 90.00 & 90.00 & 90.00 & orthorhombic & $\mathrm{Pca}_{1}[29]$ & 10.37 \\
\hline $\mathrm{Hf}_{0.88} \mathrm{Si}_{0.12} \mathrm{O}_{2}$ & 5.040 & 5.074 & 5.269 & 90.00 & 90.00 & 90.00 & orthorhombic & $\mathrm{Pca}_{1}[29]$ & 10.37 \\
\hline $\mathrm{Hf}_{0.88} \mathrm{Ge}_{0.12} \mathrm{O}_{2}$ & 5.040 & 5.074 & 5.269 & 90.00 & 90.00 & 90.00 & orthorhombic & $\mathrm{Pca}_{1}[29]$ & 10.37 \\
\hline $\mathrm{Hf}_{0.88} \mathrm{Sn}_{0.12} \mathrm{O}_{2}$ & 5.040 & 5.074 & 5.269 & 90.00 & 90.00 & 90.00 & orthorhombic & $\mathrm{Pca}_{1}[29]$ & 10.37 \\
\hline
\end{tabular}

\subsection{Electronic band structure}

The energy difference between valence band and conduction band is known as energy/band gap $\left(E_{g}\right)$. Using PBE, RPBE, PW91, WC, and PBEsol with the norm conserving pseudo potential energy/band gaps $\left(\mathrm{E}_{\mathrm{g}}\right)$ of $\mathrm{HfO}_{2}, \mathrm{Hf}_{0.88} \mathrm{Si}_{0.12} \mathrm{O}_{2}, \mathrm{Hf}_{0.88} \mathrm{Ge}_{0.12} \mathrm{O}_{2}$ and $\mathrm{Hf}_{0.88} \mathrm{Sn}_{0.12} \mathrm{O}_{2}$ crystals were calculated. Using five functionals of DFT from CASTAP by material studio 8.0 the fermi energy level was placed at zero energy level showing in Table 2. The minimum of conduction bands (MCB) and the maximum of valence bands (MVB) for two crystals has found in $\mathrm{G}$ symmetry point which have been shown in Figure 2(a)-(w), which indicate indirect band gap for $\mathrm{HfO}_{2}$. The band gap reduced after $12 \% \mathrm{Si}, 12 \% \mathrm{Ge}$ and $12 \% \mathrm{Sn}$ atom doping on $\mathrm{HfO}_{2}$, but the direct band gap found in case of all functionals. The crystal $\mathrm{HfO}_{2}$ acquired indirect band gap for fear that of GGA with PBE and its value was in $4.340 \mathrm{eV}$ shown in Figure 2(a) which was similar to its reference results $4.340 \mathrm{eV}$ [30]. Due to have accurate result using GGA with PBE, the band gap is noticed at $2.033 \mathrm{eV}$, $1.686 \mathrm{eV}$ and $3.210 \mathrm{eV}$ from Figure 2(b) to 2(d) as direct band gap crystals for $\mathrm{Hf}_{0.88} \mathrm{Si}_{0.12} \mathrm{O}_{2}, \mathrm{Hf}_{0.88} \mathrm{Ge}_{0.12} \mathrm{O}_{2}$ and $\mathrm{Hf}_{0.88} \mathrm{Sn}_{0.12} \mathrm{O}_{2}$. Moreover, for functional of GGA with RPBE, the band gap for $\mathrm{HfO}_{2}, \mathrm{Hf}_{0.88} \mathrm{Si}_{0.12} \mathrm{O}_{2}, \mathrm{Hf}_{0.88} \mathrm{Ge}_{0.12} \mathrm{O}_{2}$ and $\mathrm{Hf}_{0.88} \mathrm{Sn}_{0.12} \mathrm{O}_{2}$ is recorded at $4.427 \mathrm{eV}, 2.093 \mathrm{eV}, 1.744 \mathrm{eV}$ and 3.262eV shown in Figure 2(e) and 2(h) also having the direct band gap crystals. 
Secondly, it had also justified doing further investigations by GGA with PW91, GGA with WC, and GGA with PBEsol, the band gap for $\mathrm{HfO}_{2}, \mathrm{Hf}_{0.88} \mathrm{Si}_{0.12} \mathrm{O}_{2}, \mathrm{Hf}_{0.88} \mathrm{Ge}_{0.12} \mathrm{O}_{2}$ and $\mathrm{Hf}_{0.88} \mathrm{Sn}_{0.12} \mathrm{O}_{2}$ are at $4.333 \mathrm{eV}, 2.032 \mathrm{eV}, 1.675 \mathrm{eV}$ and $3.172 \mathrm{eV}$, respectively using GGA with PW91, at $4.252 \mathrm{eV}, 2.002 \mathrm{eV}, 1.632 \mathrm{eV}$ and $3.086 \mathrm{eV}$, respectively using GGA with WC, and at $4.245 \mathrm{eV}, 2.001 \mathrm{eV}, 1.629 \mathrm{eV}$, and $3.076 \mathrm{eV}$, respectively using GGA with PBEsol shown in Figure 2(i) and 2(w).

The comparative study focused that the five GGA methods provided similar results but GGA with PBE is considered as the standard method and this method provides similar reference result at $4.340 \mathrm{eV}$ for mother crystal $\mathrm{HfO}_{2}$. The most noticeable change is found after $12 \% \mathrm{Si}, 12 \% \mathrm{Ge}$, and $12 \% \mathrm{Sn}$ doping in the type of band structure that the $\mathrm{HfO}_{2}$ showed the indirect band gap which are converted in direct band gap for $\mathrm{Hf}_{0.88} \mathrm{Si}_{0.12} \mathrm{O}_{2}, \mathrm{Hf}_{0.88} \mathrm{Ge}_{0.12} \mathrm{O}_{2}$, and $\mathrm{Hf}_{0.88} \mathrm{Sn}_{0.12} \mathrm{O}_{2}$. Furthermore, the $\mathrm{Hf}_{0.88} \mathrm{Ge}_{0.12} \mathrm{O}_{2}$ crystal has the lowest bandgap (1.686 eV) among $\mathrm{HfO}_{2}, \mathrm{Hf}_{0.88} \mathrm{Si}_{0}$.

Table 2. Band gap for $\mathrm{HfO}_{2}, \mathrm{Hf}_{0.88} \mathrm{Si}_{0.12} \mathrm{O}_{2} \mathrm{Hf}_{0.88} \mathrm{Ge}_{0.12} \mathrm{O}_{2}$ and $\mathrm{Hf}_{0.88} \mathrm{Sn}_{0.12} \mathrm{O}_{2}$

\begin{tabular}{|lllllll|}
\hline $\begin{array}{l}\text { Crystals/ } \\
\text { functional }\end{array}$ & $\begin{array}{l}\text { GGA with } \\
\text { PBE }\end{array}$ & $\begin{array}{l}\text { GGA with } \\
\text { RPBE }\end{array}$ & $\begin{array}{l}\text { GGA with } \\
\text { PW91 }\end{array}$ & $\begin{array}{l}\text { GGA with } \\
\text { WC }\end{array}$ & $\begin{array}{l}\text { GGA with } \\
\text { PBESOL }\end{array}$ & Reference \\
\hline $\mathrm{HfO}_{2}$ & $4.340 \mathrm{eV}$ & $4.427 \mathrm{eV}$ & $4.333 \mathrm{eV}$ & $4.252 \mathrm{eV}$ & $4.245 \mathrm{eV}$ & $4.340[30]$ \\
\hline $\mathrm{Hf}_{0.88} \mathrm{Si}_{0.12} \mathrm{O}_{2}$ & $2.033 \mathrm{eV}$ & $2.093 \mathrm{eV}$ & $2.032 \mathrm{eV}$ & $2.002 \mathrm{eV}$ & $2.001 \mathrm{eV}$ & $\begin{array}{l}\text { Newly } \\
\text { Predicted }\end{array}$ \\
\hline $\mathrm{Hf}_{0.88} \mathrm{Ge}_{0.12} \mathrm{O}_{2}$ & $1.686 \mathrm{eV}$ & $1.744 \mathrm{eV}$ & $1.675 \mathrm{eV}$ & $1.632 \mathrm{eV}$ & $1.629 \mathrm{eV}$ & $\begin{array}{l}\text { Newly } \\
\text { Predicted }\end{array}$ \\
\hline $\mathrm{Hf}_{0.88} \mathrm{Sn}_{0.12} \mathrm{O}_{2}$ & $3.210 \mathrm{eV}$ & $3.262 \mathrm{eV}$ & $3.172 \mathrm{eV}$ & $3.086 \mathrm{eV}$ & $3.076 \mathrm{eV}$ & $\begin{array}{l}\text { Newly } \\
\text { Predicted }\end{array}$ \\
\hline
\end{tabular}

\subsection{The Density of states and Partial density of state}

The density of the state indicates the point of electronic band structures and the split of an orbital. The GGA with PBE method was used to calculate the density of states (DOS) of $\mathrm{Hf}, \mathrm{Si}$, Ge, $\mathrm{Sn}$ and $\mathrm{O}$ atoms of $\mathrm{HfO}_{2}, \mathrm{Hf}_{0.88} \mathrm{Si}_{0.12} \mathrm{O}_{2} \mathrm{Hf}_{0.88} \mathrm{Ge}_{0.12} \mathrm{O}_{2}$ and $\mathrm{Hf}_{0.88} \mathrm{Sn}_{0.12} \mathrm{O}_{2}$ crystals show in figure $3(\mathrm{a})$. Secondly, the conduction band found at the DOS of $\mathrm{HfO}_{2}, \mathrm{Hf}_{0.88} \mathrm{Si}_{0.12} \mathrm{O}_{2}, \mathrm{Hf}_{0.88} \mathrm{Ge}_{0.12} \mathrm{O}_{2}$ and $\mathrm{Hf}_{0.88} \mathrm{Sn}_{0.12} \mathrm{O}_{2}$ crystals at $0.00 \mathrm{eV}$ to $5 \mathrm{eV}$. The DOS of the valance band is found at -0.1 to -5 electron/eV, while the DOS of the conduction band is recorded at about 10 to 20 electron/eV. To compare the s, $p$, and d orbitals for both doping and undoped, the orbitals for $\mathrm{Hf}_{0.88} \mathrm{Si}_{0.12} \mathrm{O}_{2}$ $\mathrm{Hf}_{0.88} \mathrm{Ge}_{0.12} \mathrm{O}_{2}$ and $\mathrm{Hf}_{0.88} \mathrm{Sn}_{0.12} \mathrm{O}_{2}$ are much higher than $\mathrm{HfO}_{2}$, and it can be said that the $\mathrm{Si}$, Ge and $\mathrm{Sn}$ doping on $\mathrm{HfO}_{2}$ has increased the DOS of any crystal showing in figures $3 a, 3 b, 3 c, 3 d$, and $3 e$.

The electronic partial density of states (PDOS) of $\mathrm{HfO}_{2}, \mathrm{Hf}_{0.88} \mathrm{Si}_{0.12} \mathrm{O}_{2}, \mathrm{Hf}_{0.88} \mathrm{Ge}_{0.12} \mathrm{O}_{2}$, and $\mathrm{Hf}_{0.88} \mathrm{Sn}_{0.12} \mathrm{O}_{2}$ crystals consist of $6 \mathrm{~s}^{2}, 5 \mathrm{p}^{6}$, $4 f^{14}, 5 d^{2}$ orbital for a Hf atom, $3 s^{2}, 2 p^{6}$ orbital for Si atom, and $4 s^{2}, 3 p^{6}, 3 d^{10}$ orbital for Ge atom, $4 d^{10}, 5 s^{2}, 5 p^{2}$ for Sn atom and $2 s$ and $2 p$ orbital for $\mathrm{O}$ atom, are plotted in figures $3(\mathrm{~b})$ to $3(\mathrm{e})$. It can be seen that the Fermi level $\left(E_{F}\right)$ is close to the maximum valence band (MVB) and the maximum conduction band (MCV). Figure 3(f) to 3(p) show that how the individual atom can contribute to create the DOS and PDOS, while the orbital of Si, Ge and Sn can significantly bestow to diminish the band gap. The p-orbital showed a high DOS close to the $\mathrm{E}_{\mathrm{F}}$, which become visible as a broad peak with a width of -5.0 to $-1.0 \mathrm{eV}$ belongs to the $0-2 \mathrm{p}$ for $\mathrm{HfO}_{2}, \mathrm{Hf}_{0.88} \mathrm{Si}_{0.12} \mathrm{O}_{2}$, $\mathrm{Hf}_{0.88} \mathrm{Ge}_{0.12} \mathrm{O}_{2}$, and $\mathrm{Hf}_{0.88} \mathrm{Sn}_{0.12} \mathrm{O}_{2}$ crystals. Two peaks within range in 6-9 eV for O-2s states was observed. Regarding the $\mathrm{Hf}$ atoms, it has 3 clear peaks located at minor energies of about -3.0, and $-2.0 \mathrm{eV}$ for $4 \mathrm{f}$ states and $2.0 \mathrm{eV}$ for $5 \mathrm{p}$. Furthermore, Si atom has three significant peaks at -3.0 and $7.5 \mathrm{eV}$ for $3 p$, another peaks at $2.5 \mathrm{eV}$ for $3 \mathrm{~s}$. Ge atom has very small peaks at $-1.5 \mathrm{eV}, 1.0 \mathrm{eV}$, and $7.5 \mathrm{eV}$ for $3 d, 4 s$ and $4 p$ those peaks are contributed for MVB and MCB. The Sn-4d, $5 p$ and $5 s$ showed sharp peaks at about $-1.0,7.5$, and 4.9 $\mathrm{eV}$, respectively.

\subsection{Optical Properties}

\subsubsection{Reflectivity}

Reflectivity focuses on how much light is reflected from the material surface area with the amount of light incident on the material. The reflection coefficient $(R)$ can be obtained by combining both the electric and magnetic fields of the surface for a normal event on a flat surface. In this investigation, the reflectivity of $\mathrm{HfO}_{2}, \mathrm{Hf}_{0.88} \mathrm{Si}_{0.12} \mathrm{O}_{2}, \mathrm{Hf}_{0.88} \mathrm{Ge}_{0.12} \mathrm{O}_{2}$, and $\mathrm{Hf}_{0.88} \mathrm{Sn}_{0.12} \mathrm{O}_{2}$ is shown in figure 4. The initial 
reflectivity of $\mathrm{HfO}_{2}$ has recorded 0.16 and with the increase of energy it increases. The less reflectivity means more efficient quantum dots. After doping $\mathrm{Si} \%, \mathrm{Ge} \%$ and $\mathrm{Sn} \%$ the initial reflectivity has recorded at $0.17,18$, and 16 which decrease with the increase of energy and proved $\mathrm{Hf}_{0.88} \mathrm{Si}_{0.12} \mathrm{O}_{2}, \mathrm{Hf}_{0.88} \mathrm{Ge}_{0.12} \mathrm{O}_{2}$, and $\mathrm{Hf}_{0.88} \mathrm{Sn}_{0.12} \mathrm{O}_{2}$ showed the similar patterns, and the highest reflectivity is observed for Ge atom doping.

\subsubsection{Absorption}

The absorption coefficient provides useful data when these materials are used in solar energy conversion for optimal efficiency, and the absorption spectrum of a material depends on the nature of the energy band gap which follows the indirect band gap usually absorbs more temperature than the direct band gap semiconductor device, because there are fewer phonons at low temperature. The absorption spectrum of $\mathrm{Hf}_{0.88} \mathrm{Si}_{0.12} \mathrm{O}_{2}, \mathrm{Hf}_{0.88} \mathrm{Ge}_{0.12} \mathrm{O}_{2}$ and $\mathrm{Hf}_{0.88} \mathrm{Sn}_{0.12} \mathrm{O}_{2}$ is higher than $\mathrm{HfO}_{2}$. From figure 5 , it is clear that with the increase of energy the absorption of materials, for instance $\mathrm{HfO}_{2}, \mathrm{Hf}_{0.88} \mathrm{Si}_{0.12} \mathrm{O}_{2}, \mathrm{Hf}_{0.88} \mathrm{Ge}_{0.12} \mathrm{O}_{2}$ and $\mathrm{Hf}_{0.88} \mathrm{Sn}_{0.12} \mathrm{O}_{2}$, is increased, but $\mathrm{Hf}_{0.88} \mathrm{Ge}_{0.12} \mathrm{O}_{2}$ shows better value of absorption than $\mathrm{HfO}_{2}, \mathrm{Hf}_{0.88} \mathrm{Si}_{0.12} \mathrm{O}_{2}$, and $\mathrm{Hf}_{0.88} \mathrm{Sn}_{0.12} \mathrm{O}_{2}$.

\subsubsection{Refractive Index}

The real part of refractive index indicates the amount of light refracted or curved and the imaginary or hypothetical part of refractive index indicates the mass loss coefficient and also determines the amount of emission when light travels through the materials. These optical properties like refractive index helps in quality evaluation of band gap persuaded structures for unremitting and optimal absorption of broad band spectral sources. Figure 6 displays the refractive index as a function of photon energy where the real part and the imaginary part for both of the $\mathrm{HfO}_{2}, \mathrm{Hf}_{0.88} \mathrm{Si}_{0.12} \mathrm{O}_{2}, \mathrm{Hf}_{0.88} \mathrm{Ge}_{0.12} \mathrm{O}_{2}$ and $\mathrm{Hf}_{0.88} \mathrm{Sn}_{0.12} \mathrm{O}_{2}$ are mentioned, showing an inverse pattern. At initial point of photon energy, the refractive index is higher for real part while the imaginary part is almost closed to $1.0 \mathrm{eV}$, and afterwards they follow a constant pattern with slightly different values of refractive index. It is same for both undoped and doped.

\subsubsection{Dielectric Function}

The dielectric function is most important for semiconductor device, such as diode, MOSFETs and RRAM etc. The dielectric functions are calculated in the linear optical response system within the electric dipole approximation. The necessary momentum matrix elements are obtain by using the calculated wave functions from our pragmatic pseudo potentials. Dielectric functions that describe the materials at the nanoscale are needed, opening the way to the interpretation of experimental data and design of the composites to obtain desired optical behavior [31]. The dielectric function explains how an electric field wills exertion with such an oscillating light wave element. The dielectric function is very necessary tool to investigate their optical properties which is related with adsorption properties as following equation for solid.

$\varepsilon=\varepsilon_{1}(\omega)+i \varepsilon_{2}(\omega)$

Here, the main part or real part of the complex dielectric function $\varepsilon_{1}(\omega)$ indicates the polarization and energy storage potential in the electric field of the material due to the propagated light, while the imaginary part i $\varepsilon_{2}(\omega)$ represents the amount of absorption in a material, and discharging of charge storage. The probability of photon absorption for the band structure of any material is closely related to the imaginary portion of the dielectric function. A significant amount of imaginary dielectric function; it represents several inter-band transitions between $\mathrm{VB}$ and $\mathrm{CB}$. From figure 7, the real portion is always higher than the imaginary part within the energy at $1.0 \mathrm{eV}$ to $1.8 \mathrm{eV}$, and it must concluded that it is the energy storage materials than discharging potential materials which helps to elaborate their applications in MOSFETs and RRAM. In case of energy range from $2 \mathrm{eV}$ to $4 \mathrm{eV}$ the imaginary part shows higher value than real portion for $\mathrm{HfO}_{2}, \mathrm{Hf}_{0.88} \mathrm{Si}_{0.12} \mathrm{O}_{2}, \mathrm{Hf}_{0.88} \mathrm{Ge}_{0.12} \mathrm{O}_{2}$ and $\mathrm{Hf}_{0.88} \mathrm{Sn}_{0.12} \mathrm{O}_{2}$.

\subsubsection{Conductivity}

A contact-free quantitative measurement sensitive to most charged reactions known as conductivity can be described in terms of band gap and electrical conduction at high (optical) frequencies[32]. Electronic conduction is nothing but putting electrons in the conduction band and by providing enough energy to an electron bound to the atoms this objective can be accomplished and can be made the electron free by breaking the bond. By shining the material with light this can easily be performed which photons do have an energy allowing the breaking of the bonds. In a solid state language, electrons can move from the valence to the conduction band by the support of photon leaving a hole in the valence band and an electrical conduction of the material will processed due to the free electron and hole. Figure 8 depicts the comparative study of the conductivity value of $\mathrm{HfO}_{2}, \mathrm{Hf}_{0.88} \mathrm{Si}_{0.12} \mathrm{O}_{2}, \mathrm{Hf}_{0.88} \mathrm{Ge}_{0.12} \mathrm{O}_{2}$ and $\mathrm{Hf}_{0.88} \mathrm{Sn}_{0.12} \mathrm{O}_{2}$ crystals. The conductivity values of both real and imaginary parts starting from almost zero at $0.0 \mathrm{eV}$. The real part of conductivity 
increased with a similar trend for $\mathrm{HfO}_{2}, \mathrm{Hf}_{0.88} \mathrm{Si}_{0.12} \mathrm{O}_{2}, \mathrm{Hf}_{0.88} \mathrm{Ge}_{0.12} \mathrm{O}_{2}$ and $\mathrm{Hf}_{0.88} \mathrm{Sn}_{0.12} \mathrm{O}_{2}$ in the energy range from $0 \mathrm{eV}$ to $5.0 \mathrm{eV}$ and reached conductivity real peaked value 2.8 and 3.0 , but the conductivity value of $\mathrm{Hf}_{0.88} \mathrm{Ge}_{0.12} \mathrm{O}_{2}$ within energy range 1.0 to $3.0 \mathrm{eV}$ is higher than $\mathrm{HfO}_{2}, \mathrm{Hf}_{0.88} \mathrm{Si}_{0.12} \mathrm{O}_{2}, \mathrm{Hf}_{0.88} \mathrm{Ge}_{0.12} \mathrm{O}_{2}$ and $\mathrm{Hf}_{0.88} \mathrm{Sn}_{0.12} \mathrm{O}_{2}$. On the other hand, the imaginary part values of $\mathrm{HfO}_{2}$, $\mathrm{Hf}_{0.88} \mathrm{Si}_{0.12} \mathrm{O}_{2}, \mathrm{Hf}_{0.88} \mathrm{Ge}_{0.12} \mathrm{O}_{2}$ and $\mathrm{Hf}_{0.88} \mathrm{Sn}_{0.12} \mathrm{O}_{2}$ are gradually declined after Fermi energy in the energy range from $3.0 \mathrm{eV}$ and reached conductivity imaginary peaked values-2.1and -5.0 .

\subsubsection{Loss function}

There is a number of optical parameter but energy loss function is the most significant optical parameter which is nothing but the loss of photon energy during the reaction and which is denoted by L. During passing through the element electrons losses energy and here function $L$ describes the impetuous energy loss of electrons. The plasma resonance and the corresponding frequency which is known as plasma frequencies are very much connected with the peaks of the $L$ function [33]. This function has capability to cover the full energy range and has involvement in scattered elastic and non-scattered electrons and also in stimulating valence inter-band transitions or electrons in the outer shell of the atom [34].

Secondly, the loss function is a crucial part of optical properties which is composed of two regions of photon energy parts such as the lower photon energy part and higher photon energy part for crystal materials. The energy loss function is closely related to the dielectric function of the photocatalyst materials within the range of the dielectric theory validation. In the energy loss function dielectric function reflects the response of a semiconductor to an external electromagnetic perturbation. The calculated exploration of loss function values for $\mathrm{HfO}_{2}, \mathrm{Hf}_{0.88} \mathrm{Si}_{0.12} \mathrm{O}_{2}, \mathrm{Hf}_{0.88} \mathrm{Ge}_{0.12} \mathrm{O}_{2}$ and $\mathrm{Hf}_{0.88} \mathrm{Sn}_{0.12} \mathrm{O}_{2}$ illustrates in figure 9. It can be seen that loss function of $\mathrm{Hf}_{0.88} \mathrm{Ge}_{0.12} \mathrm{O}_{2}$ higher than $\mathrm{HfO}_{2}, \mathrm{Hf}_{0.88} \mathrm{Si}_{0.12} \mathrm{O}_{2}$, and $\mathrm{Hf}_{0.88} \mathrm{Sn}_{0.12} \mathrm{O}_{2}$.

\subsection{Molecular electrostatic potential maps (EPM)}

The sequence of charge distribution of a molecule due to the properties of the nucleus and the nature of the electrostatic potential energy can be revealed by the electrostatic potential map which is nothing but the charge distribution of molecules in three dimensions. An area of higher than average electrostatic potential energy indicates the presence of a physically powerful positive charge or a weaker negative charger. The positive charge of the nucleus established the high potential energy value point to the absence of negative charge (less screening of the nucleus), which means that there are fewer electrons in this area. The discussion is true with low electrostatic potential which point outs an abundance of electrons. This feature of electrostatic potential can also be extrapolated to molecules. This property of electrostatic potentials can be extrapolated to molecules as well. In the figures 10 (a) to 10 (d), the positive electrostatic potential regions are highlighted in blue (electrophilic sites), where red represents the nucleophilic invasion region. Positively charged regions are observed to be significantly higher than negatively charged regions, indicating that the electrophilic groups of these molecules are more attracted to nucleophilic.

\subsection{Aquatic toxicity}

Aquatic toxicity is the study of the effects of chemicals and other ethnographic and natural materials and the activity on aquatic organisms that affect communities and ecosystems through individual organisms. In case of the safety of the aquatic organism, the toxicity of used materials is the crucial fact before approval to use. To create a toxicity profile for the predicted bio-inorganic crystals, computational tools through various parameters, for example AMES toxicity, honey bees, rats and fish, carcinogenicity and inhibition have been implemented. There is no response to AMES toxicity except for all crystals. Second, there is no barrier nature by all crystals by any organism, so there is no chance of entering living cells to create damage or adverse effects for other diseases, even after entering the living cell, the carcinogenic effect is almost absent. On the other hand, Table 3 Shows that the solubility of these crystals is near to organic compounds near to -3.0 or below. The innovative feedback from these crystals is explained the effect of oxygen atoms that the solubility is changed due to change in the electronegative atoms in such a way that it does not depend on electro negativity but related to size. With increasing the size, it grows up, and similar to other parameters. Finally, it could be said that these crystals are the eco-friendly materials. 
Table 3

Aquatic and non aquatic toxicity

\begin{tabular}{|c|c|c|c|c|c|c|c|c|c|}
\hline & $\begin{array}{l}\text { AMES } \\
\text { toxicity }\end{array}$ & Inhibition & Carcinogenicity & $\begin{array}{l}\text { Water } \\
\text { solubility, } \\
\text { Log S }\end{array}$ & $\begin{array}{l}\text { Acute } \\
\text { Oral } \\
\text { Toxicity, } \\
\text { kg/mol }\end{array}$ & $\begin{array}{l}\text { Oral Rat } \\
\text { Acute } \\
\text { Toxicity } \\
(\mathrm{LD} 50) \\
(\mathrm{mol} / \mathrm{kg})\end{array}$ & $\begin{array}{l}\text { Honey } \\
\text { Bee } \\
\text { Toxicity }\end{array}$ & $\begin{array}{l}\text { Fish } \\
\text { Toxicity } \\
\text { pLC50 } \\
\text { mg/L }\end{array}$ & $\begin{array}{l}\text { T.Pyriformis } \\
\text { toxicity } \\
\text { (log } \mu \mathrm{g} / \mathrm{L})\end{array}$ \\
\hline $\mathrm{HfO}_{2}$ & No & No & No & -3.6414 & 0.5170 & 2.6333 & High & $\begin{array}{l}1.3987 \\
\text { (low) }\end{array}$ & $\begin{array}{l}0.5238 \\
\text { (High) }\end{array}$ \\
\hline $\mathrm{Hf}_{0.88} \mathrm{Si}_{0.12} \mathrm{O}_{2}$ & No & No & No & -3.8883 & 0.5163 & 2.6289 & High & $\begin{array}{l}1.1513 \\
\text { (low) }\end{array}$ & $\begin{array}{l}0.6060 \\
\text { (High) }\end{array}$ \\
\hline $\mathrm{Hf}_{0.88} \mathrm{Ge}_{0.12} \mathrm{O}_{2}$ & No & No & No & -3.7058 & 0.5227 & 2.6338 & High & $\begin{array}{l}1.3933 \\
\text { (low) }\end{array}$ & $\begin{array}{l}0.5277 \\
\text { (High) }\end{array}$ \\
\hline $\mathrm{Hf}_{0.88} \mathrm{Sn}_{0.12} \mathrm{O}_{2}$ & No & No & No & -3.7058 & 3.869 & 2.6338 & low & $\begin{array}{l}1.3933 \\
\text { low }\end{array}$ & $\begin{array}{l}0.5277 \\
\text { (High) }\end{array}$ \\
\hline
\end{tabular}

\subsection{Conclusion}

The purpose of this work was to computationally investigate the crystal structure, electronic, and optical properties of $\mathrm{HfO}_{2}$, $\mathrm{Hf}_{0.88} \mathrm{Si}_{0.12} \mathrm{O}_{2}, \mathrm{Hf}_{0.88} \mathrm{Ge}_{0.12} \mathrm{O}_{2}$, and $\mathrm{Hf}_{0.88} \mathrm{Sn}_{0.12} \mathrm{O}_{2}$ using the quantum of five different correlations functionals, for example GGA with PBE, GGA with PBE, GGA with RPBE, GGA with PW91, GGA with WC, and GGA with PBE $_{\text {sol }}$. We ended up by using Perdew-BurkeErnzerhof (PBE) in measuring lattice parameters, energy bandgap and optical properties of the investigated materials. The calculated energy gaps of mother crystal $\mathrm{HfO}_{2}$ are similar to the reference value $(4.340 \mathrm{eV})$. It is noticed that the $12 \% \mathrm{Si}, 12 \% \mathrm{Ge}$ and $12 \% \mathrm{Sn}$ atom doping on $\mathrm{HfO}_{2}$, the band gap has reduced and the $\mathrm{Hf}_{0.88} \mathrm{Ge}_{0.12} \mathrm{O}_{2}$ crystal has a lower power band gap (1.686 eV) among $\mathrm{HfO}_{2}$, $\mathrm{Hf}_{0.88} \mathrm{Si}_{0.12} \mathrm{O}_{2}$, and $\mathrm{Hf}_{0.88} \mathrm{Sn}_{0.12} \mathrm{O}_{2}$ crystals. The optical properties, due to $\mathrm{Si}, \mathrm{Ge}$ and $\mathrm{Sn}$ doping, has changed. The optical dielectric function, absorption, reflectivity, loss function, and conductivity of $\mathrm{Hf}_{0.88} \mathrm{Si}_{0.12} \mathrm{O}_{2}, \mathrm{Hf}_{0.88} \mathrm{Ge}_{0.12} \mathrm{O}_{2}$, and $\mathrm{Hf}_{0.88} \mathrm{Sn}_{0.12} \mathrm{O}_{2}$ are greater than $\mathrm{HfO}_{2}$. Secondly, the molecular electrostatic potential maps (EPM), which explained the charge distribution of a molecule due to the properties of the nucleus and the nature of the electrostatic potential energy, has been calculated, and explain the factor of electronegativity for producing charge distribution. Moreover aquatic toxicity also investigated for $\mathrm{HfO}_{2}, \mathrm{Hf}_{0.88} \mathrm{Si}_{0.12} \mathrm{O}_{2}, \mathrm{Hf}_{0.88} \mathrm{Ge}_{0.12} \mathrm{O}_{2}$, and $\mathrm{Hf}_{0.88} \mathrm{Sn}_{0.12} \mathrm{O}_{2}$ crystals. Those crystals have no aquatic toxicity, such as AMES toxicity, honey bees toxicity, rats toxicity, fish toxicity, carcinogenicity toxicity, inhibition toxicity and it could be said that these crystals are the eco-friendly materials. Finally all computational results reported that $\mathrm{Si} \%, \mathrm{Ge} \%$ and $\mathrm{Sn} \%$ doping in $\mathrm{HfO}_{2}$ is almost acted as a promising eco-friendly semiconductor material for MOSFETs and RRAM whereas the Ge doping is the more efficacy.

\section{References}

1. Colinge, J.-P.: Multiple-gate soi mosfets. Solid-State Electronics 48, 897-905 (2004)

2. Lundstrom, M., Ren, Z.: Essential physics of carrier transport in nanoscale MOSFETs. IEEE Trans. Electron Devices 49, 133-141 (2002)

3. Djeffal, F.M., M.; Benhaya: A, "A two-dimensional analytical analysis of subthreshold behavior to study the scaling capability of nanoscale graded channel gate stack DG MOSFETs". Physica E 41, 1872-1877 (2009)

4. Swain, S.K.D., A.; Adak, S.; Pati, S.K.; Sarkar, Kumar, C.: Influence of channel length and high-K oxide thickness on subthreshold analog/RF performance of graded channel and gate stack DG-MOSFETs. Microelectron. Reliab. 61, 24-29 (2016)

5. Cheng, C.-H., Chin, A.: Low-leakage-current DRAM-like memory using a one-transistor ferroelectric MOSFET with a Hf-based gate dielectric. IEEE electron device letters 35, 138-140 (2013)

6. Yoon, C., Moon, S., Shin, C.: Study of a hysteresis window of FinFET and fully-depleted silicon-on-insulator (FDSOI) MOSFET with ferroelectric capacitor. Nano Convergence 7, 1-7 (2020)

7. Richel, P.L.A., Wathelet, B., Wathelet, J.-P., Paquot, M.: "Microwave-assisted conversion of carbohydrates; State of the art and outlook.". C. R. Chim. 14, 224-234 (2011). https://doi.org/10.1016/j.crci.2010.04.004

8. Min, B.D., S.I.V.A.P.R.A.S.A.D.; Çelik-Butler, Z.; Wang, F.; Zlotnicka, A.; Tseng, H.-H.; Tobin: Philip J, "Low-frequency noise in submicrometer MOSFETs with HfO2, HfO2/Al2O3 and HfAlOx gate stacks". IEEE Trans. Electron Devices 51, 1679-1687 (2004) 
9. Li, Y.M., Y.; Lin, W.; Dong, P.; Yang, Z.; Gong, M.; Bi, J.; Li, B.; Xi, K.; Xu: Gaobo, "Study of y-ray irradiation influence on TiN/HfO2/Si MOS capacitor by CV and DLTS". Superlattices Microstruct. 120, 313-318 (2018)

10. Hurley, P.K.O.C., E.; Monaghan, S.; Long, R.; O'Mahony, A.; Povey, I.M.; Cherkaoui, K.; MacHale, J.; Quinn, A.; Brammertz: Guy, "Structural and Electrical Properties of $\mathrm{HfO}_{2} / \mathrm{n}-\mathrm{InxGa} \mathrm{A}_{1}$-xAs structures (x: 0, 0.15, 0.3 and 0.53)". ECS transactions 25, 113 (2009)

11. Liu, C.C., E.F.; Tan, Seow, L.: Enhanced device performance of AlGaN/GaN HEMTs using HfO2 high-k dielectric for surface passivation and gate oxide. Semicond. Sci. Technol. 22, 522 (2007)

12. Pradhan, D., Das, S., Dash, T., Prasanna: Study of strained-Si p-channel MOSFETs with HfO2 gate dielectric. Superlattices Microstruct. 98, 203-207 (2016)

13. Lee, H.C., P.S.; Wu, T.Y.; Chen, Y.S.; Wang, C.C.; Tzeng, P.J.; Lin, C.H.; Chen, F.; Lien, C.H.; Tsai, M-J, "Low power and high speed bipolar switching with a thin reactive Ti buffer layer in robust HfO2 based RRAM," in 2008 IEEE International Electron Devices Meeting, 2008, pp. 1-4

14. Hsu, C.T., et al.: "High dielectric constant of RF-sputtered HfO2 thin films". Japanese journal of applied physics 31, 2501 (1992)

15. Jagannathan, $\mathrm{H}$., et al.: "Engineering high dielectric constant materials for band-edge CMOS applications". ECS transactions 16,19 (2008)

16. Al Mamun, A.M.A., Md; Habib, A.; Chakma, U.; Sikder, M.; Kumer, Ajoy; "Structural, electronic, optical properties and molecular dynamics study of $\mathrm{WO}_{3} \mathrm{~W}_{0.97} \mathrm{Ag}_{0.03} \mathrm{O}_{3}$ and $\mathrm{W}_{0.94} \mathrm{Ag}_{0.06} \mathrm{O}_{3}$ photocatalyst by the first principle of DFT study" Egyptian Journal of Chemistry, vol. 63, 2021

17. Hasan, M.M., Ajoy, K., Chakma: Unesco; "Theoretical Investigation of Doping Effect of Fe for SnWO 4 in Electronic Structure and Optical Properties: DFT Based First Principle Study". Advanced Journal of Chemistry-Section A 03, 639-644 (2020)

18. Howlader, D.H., M.S.; Chakma, U.; Kumer, A.; Islam, M.J.; Islam: Md Tawhidul; Hossain, Tomal; slam, Jahedul, "Structural geometry, electronic structure, thermo-electronic and optical properties of GaCuO2 and GaCu0. 94Fe0. 0602: a first principle approach of three DFT functionals". Mol. Simul. 44, 1-12 (2021). ;https://doi.org/10.1080/08927022.2021.1977295

19. ISLAM, M.T., Ajoy, K.U.M.E.R., HOWLADER, Debashis; CHAKMA, Kamal Bikash, C.H.A.K.M.A.: Unesco; "Electronics structure and optical properties of $\mathrm{Mg}\left(\mathrm{BiO}_{2}\right)_{4}$ and $\mathrm{Mg}\left(\mathrm{Bi}_{0.91} \mathrm{Ge}_{0.083} \mathrm{O}_{2}\right)_{4}$ : A first principle approach". Turkish Computational and Theoretical Chemistry 4, 24-31 (2020)

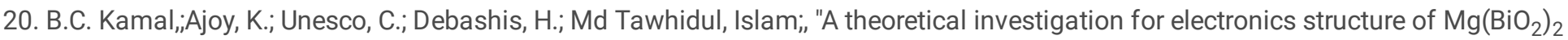
semiconductor using first principle approach," International Journal of New Chemistry, vol. 7, pp. 247-255., 2020

21. Mokit, S.U.M.A.: Chakma; Ajoy Kumer; Mohammad,Jahidul Islam, Ahsan Habib; Md Monsur Alam; "The Exploration of Structural, Electronic and Optical Properties for $\mathrm{MoS}_{2}$ and $\mathrm{Mo}_{0.95} \mathrm{~W}_{0.05} \mathrm{~S}_{2}$ Photocatalyst Effort on Wastewater Treatment using DFT Functional of First Principle Approach". Applied Journal of Environmental Engineering Science 7, 103-113 (2021)

22. C.D. Md Tawhidul Islam; Ajoy Kumer; Unesco, Howlader; "A Computational Investigation of Electronic Structure and Optical Properties of $\mathrm{AlCuO}_{2}$ and $\mathrm{AlCu}_{0.96} \mathrm{Fe}_{0.04} \mathrm{O}_{2}$ : A First Principle Approach," Orbital: Electron. J. Chem, vol. 13, 2021

23. Ali, M.I., M.J.; Rafid, M.; Ahmed, R.; Jeetu, Md; Rayhan, R.; Roy, R.; Chakma, U.; Kumer: Ajoy, "The computational screening of structural, electronic, and optical properties for $\mathrm{SiC}, \mathrm{Si}_{0.94} \mathrm{Sn}_{0.06} \mathrm{C}$, and $\mathrm{Si}_{0.88} \mathrm{Sn}_{0.12} \mathrm{C}$ lead-free photovoltaic inverters using DFT functional of first principle approach". Eurasian Chemical Communications 3, 327-338 (2021)

24. Segall, M., D.; Lindan, P.J.D.; Probert, M.Jal; Pickard, C.J.; Hasnip, P.J.; Clark, S.J.; Payne: M., C., "First-principles simulation: ideas, illustrations and the CASTEP code". J. Phys.: Condens. Matter. 14, 2717 (2002)

25. Clark, S.J.S., M.D.; Pickard, C.J.; Hasnip, P.J.; Probert, M.I.J.; Refson, K.; Payne, Mike, C.: First principles methods using CASTEP. Zeitschrift für Kristallographie-Crystalline Materials 220, 567-570 (2005)

26. Ziesche, P.K., S.; Perdew: John P; "Density functionals from LDA to GGA". Comput. Mater. Sci. 11, 122-127 (1998)

27. del Campo, J.M.G., J.L.; Trickey, S.B.; Vela, Alberto, "Non-empirical improvement of PBE and its hybrid PBE0 for general description of molecular properties," The Journal of chemical physics, vol. 136, p. 104108, 2012

28. Yang, Z.J., Zhao, K., Truhlar, Y.: DG, "Tests of the RPBE, revPBE, tau-HCTHhyb, omegaB97X-D, and MOHLYP density functional approximations and 29 others against representative databases for diverse bond energies and barrier heights in catalysis". J. Chem. Phys. 132, 164117 (2010)

29. Ajoy, K., Chakma, U., "Developing the amazing photocatalyst of $Z \mathrm{Zng}_{2} \mathrm{GeSe}_{4}, \mathrm{ZnAg}_{2} \mathrm{Ge}_{0.93} \mathrm{Fe}_{0.07} \mathrm{Se}_{4}$ and $\mathrm{ZnAg}_{2} \mathrm{Ge}_{0.8} 6 \mathrm{Fe}_{0.14} \mathrm{Se}_{4}$ through the computational explorations by four DFT functionals," Heliyon, vol. 7, p. e07467, 2021

Page $8 / 12$ 
30. Zhu, H., et al.: "Recent progress in ab initio simulations of hafnia-based gate stacks". Journal of Materials Science 47, 7399-7416 (2012)

31. Alves-Santos, M., et al.: "Dielectric functions of semiconductor nanoparticles from the optical absorption spectrum: the case of CdSe and CdS". J. Phys. Chem. C 114, 3776-3780 (2010)

32. Eichelbaum, M.S.e., R.; Karpov, A.; Dobner, C.-K.; Rosowski, F.; Trunschke, A.; Schlögl: Robert, "The microwave cavity perturbation technique for contact-free and in situ electrical conductivity measurements in catalysis and materials science". Physical Chemistry Chemical Physics 14, 1302-1312 (2012)

33. Treumann, R.A.: The electron-cyclotron maser for astrophysical application. Astron. Astrophys. Rev. 13, $229-315$ (2006)

34. Livache, C.G., N.; Gréboval, C.; Martinez, B.; Ramade, J.; Qu, J.; Triboulin, A.; Cruguel, H.; Baptiste, B.; Klotz: Stefan, "Effect of Pressure on Interband and Intraband Transition of Mercury Chalcogenide Quantum Dots". J. Phys. Chem. C 123, 13122-13130 (2019)

\section{Figures}

a)

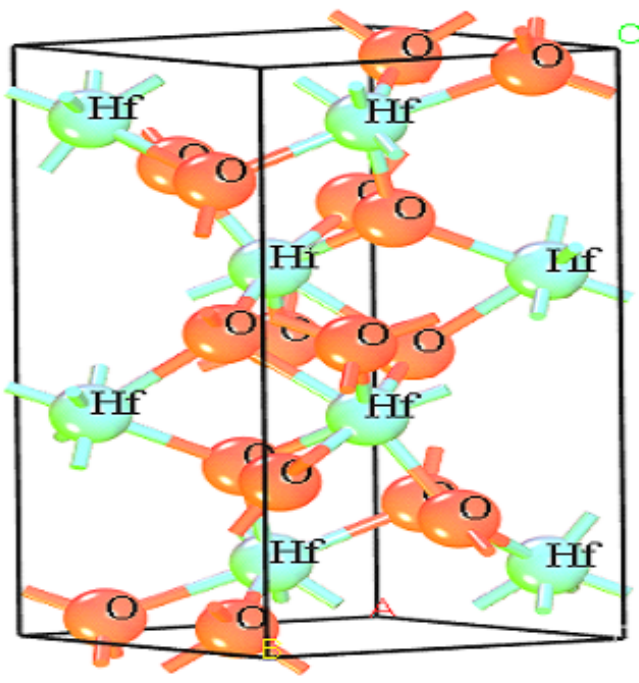

c)

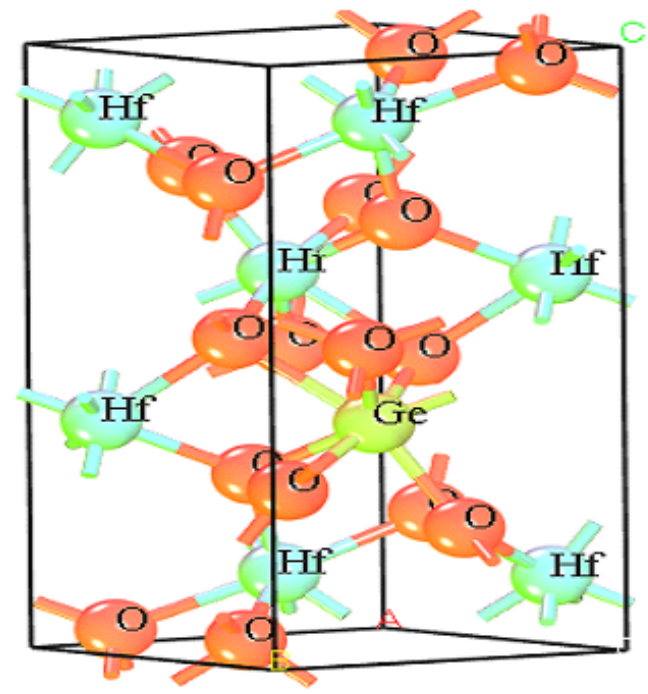

b)

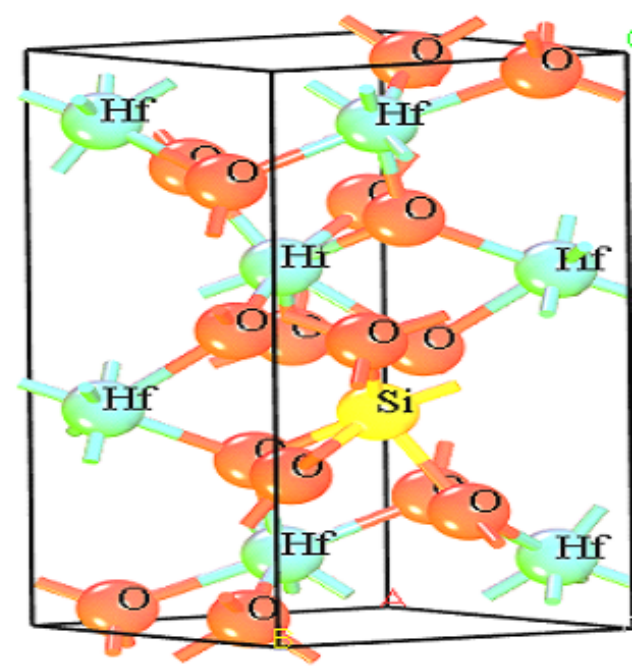

d)

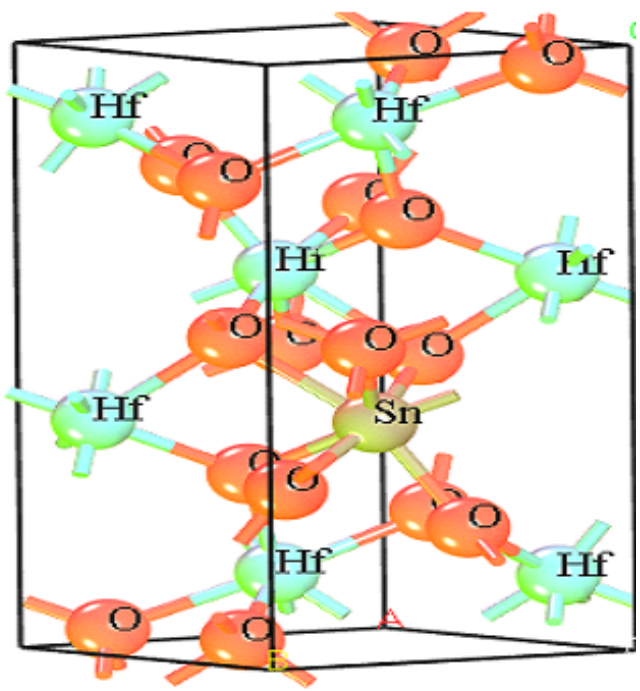

Figure 1

a) Structure for $\mathrm{HfO}_{2}$, b) Structure for $\mathrm{Hf}_{0.88} \mathrm{Si}_{0.12} \mathrm{O}_{2}$, c) Structure for $\mathrm{Hf}_{0.88} \mathrm{Ge}_{0.12} \mathrm{O}_{2}$ and d) Structure for $\mathrm{Hf}_{0.88} \mathrm{Sn}_{0.12} \mathrm{O}_{2}$. 
a) Band structure by GGA with PBE for $\mathrm{HfO}_{4}$, b) Band structure by GGA with PBE for $\mathrm{Hf}_{0.88} \mathrm{Si}_{0.12} \mathrm{O}_{4}, \mathrm{c}$ ) Band structure by GGA with PBE $\mathrm{Hf}_{0.88} \mathrm{Ge}_{0.12} \mathrm{O}_{4}$, d) Band structure by GGA with PBE for $\mathrm{Hf}_{0.88} \mathrm{Sn}_{0.12} \mathrm{O}_{4}$, e) Band structure by GGA with RPBE for $\mathrm{HfO}_{4}$, $\mathrm{f}$ ) Band structure by GGA with RPBE for $\mathrm{Hf}_{0.88} \mathrm{Si}_{0.12} \mathrm{O}_{4}, \mathrm{~g}$ ) Band structure by GGA with RPBE for $\mathrm{Hf}_{0.88} \mathrm{Ge}_{0.12} \mathrm{O}_{4}$, h) Band structure by GGA with RPBE for $\mathrm{Hf}_{0.88} \mathrm{Sn}_{0.12} \mathrm{O}_{4}$, i) Band structure by GGA with PW91for $\mathrm{HfO}_{4}$, j) Band structure by GGA with PW91 for $\mathrm{Hf}_{0.88} \mathrm{Si}_{0.12} \mathrm{O}_{4}, \mathrm{k}$ ) Band structure GGA with PW91 $\mathrm{Hf}_{0.88} \mathrm{Ge}_{0.12} \mathrm{O}_{4}$, I) Band structure by GGA with PW91for $\mathrm{Hf}_{0.88} \mathrm{Sn}_{0.12} \mathrm{O}, \mathrm{m}$ ) Band structure by GGA with WC for $\mathrm{HfO}_{4}, \mathrm{n}$ ) Band structure by GGA with WC for $\mathrm{Hf}_{0.88} \mathrm{Si}_{0.12} \mathrm{O}_{4}$, o) Band structure by GGA with WC for $\mathrm{Hf}_{0.88} \mathrm{Ge}_{0.12} \mathrm{O}_{4}, \mathrm{p}$ ) Band structure by GGA with WC for $\mathrm{Hf}_{0.88} \mathrm{Sn}_{0.12} \mathrm{O}_{4}$, q) Band structure by GGA with PBESOL for $\mathrm{HfO}_{4}, \mathrm{~s}$ ) Band structure by GGA with PBESOL for $\mathrm{Hf}_{0.88} \mathrm{Si}_{0.12} \mathrm{O}_{4}, \mathrm{t}$ ) Band structure by GGA with PBESOL for $\mathrm{Hf}_{0.88} \mathrm{Ge}_{0.12} \mathrm{O}_{4}$ and w) Band structure by GGA with PBESOL for $\mathrm{Hf}_{0.88} \mathrm{Sn}_{0.12} \mathrm{O}_{4}$.

\section{Figure 3}

a) Total density of states for $\mathrm{HfO}_{2}, \mathrm{Hf}_{0.88} \mathrm{Si}_{0.12} \mathrm{O}_{2} \mathrm{Hf}_{0.88} \mathrm{Ge}_{0.12} \mathrm{O}_{2}$ and $\mathrm{Hf}_{0.88} \mathrm{Sn}_{0.12} \mathrm{O}_{2}$, b) Partial density of states for $\mathrm{HfO}_{2}, \mathrm{c}$ ) Partial density of states for $\mathrm{Hf}_{0.88} \mathrm{Si}_{0.12} \mathrm{O}_{2}$, d) Partial density of states for $\mathrm{Hf}_{0.88} \mathrm{Ge}_{0.12} \mathrm{O}_{2}$, e) Partial density of states for $\left.\mathrm{Hf}_{0.88} \mathrm{Sn}_{0.12} \mathrm{O}_{2}, \mathrm{f}\right) \mathrm{Hf}$ atom for $\mathrm{HfO}_{2}$, h) $\mathrm{Hf}$ atom for $\mathrm{Hf}_{0.88} \mathrm{Si}_{0.12} \mathrm{O}_{2}$, i) Si atom for $\mathrm{Hf}_{0.88} \mathrm{Si}_{0.12} \mathrm{O}_{2}, \mathrm{j}$ ) O atom for $\mathrm{Hf}_{0.88} \mathrm{Si}_{0.12} \mathrm{O}_{2}, \mathrm{k}$ ) Hf atom for $\mathrm{Hf}_{0.88} \mathrm{Ge}_{0.12} \mathrm{O}_{2}, \mathrm{l}$ ) Ge atom for $\left.\mathrm{Hf}_{0.88} \mathrm{Ge}_{0.12} \mathrm{O}_{2}, \mathrm{~m}\right) \mathrm{O}$ atom for $\left.\mathrm{Hf}_{0.88} \mathrm{Ge}_{0.12} \mathrm{O}_{2}, \mathrm{n}\right) \mathrm{Hf}$ atom for $\mathrm{Hf}_{0.88} \mathrm{Sn}_{0.12} \mathrm{O}_{2}, \mathrm{O}$ ) Sn atom for $\left.\mathrm{Hf}_{0.88} \mathrm{Sn}_{0.12} \mathrm{O}_{2}, \mathrm{p}\right) \mathrm{O}$ atom for $\mathrm{Hf}_{0.88} \mathrm{Sn}_{0.12} \mathrm{O}_{2}$.

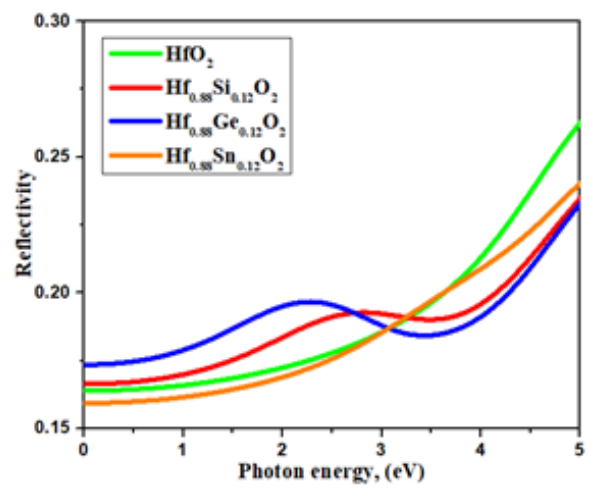

\section{Figure 4}

Reflectivity

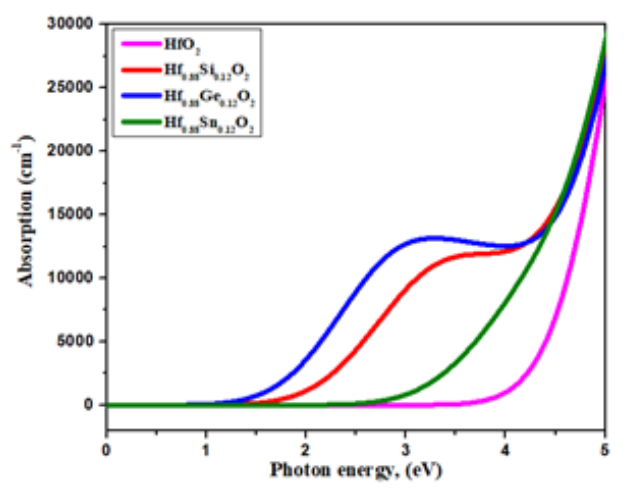

Figure 5

Absorption 


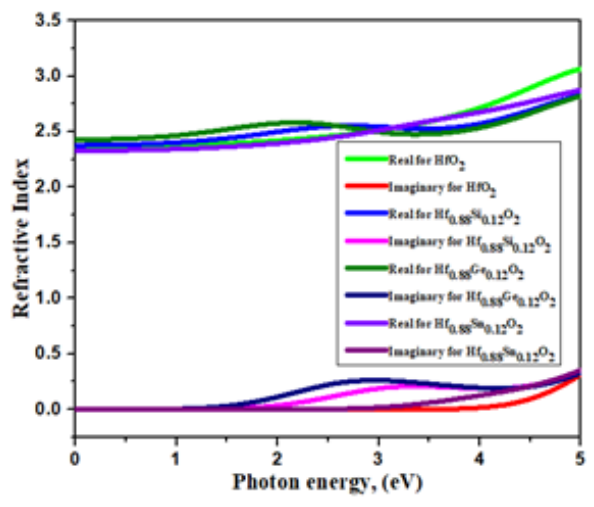

Figure 6

Refractive Index

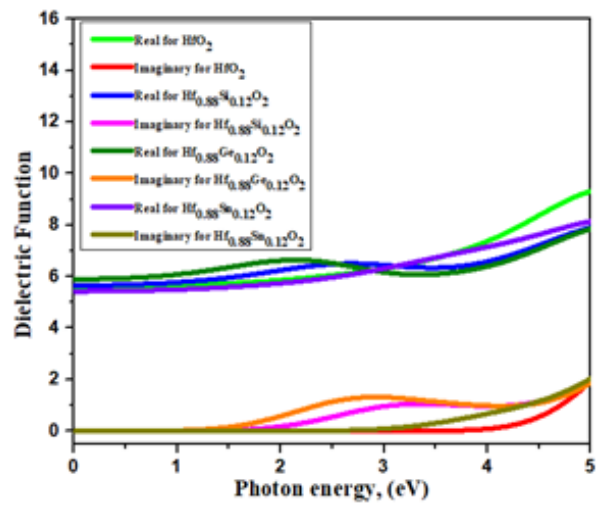

Figure 7

Dielectric Function

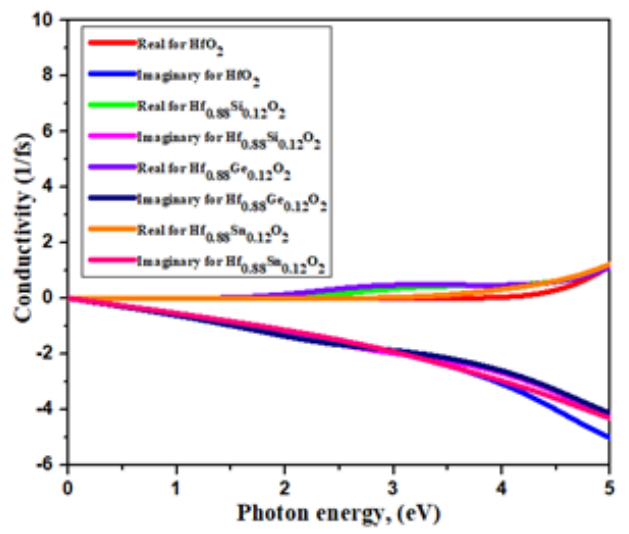

Figure 8

Conductivity 


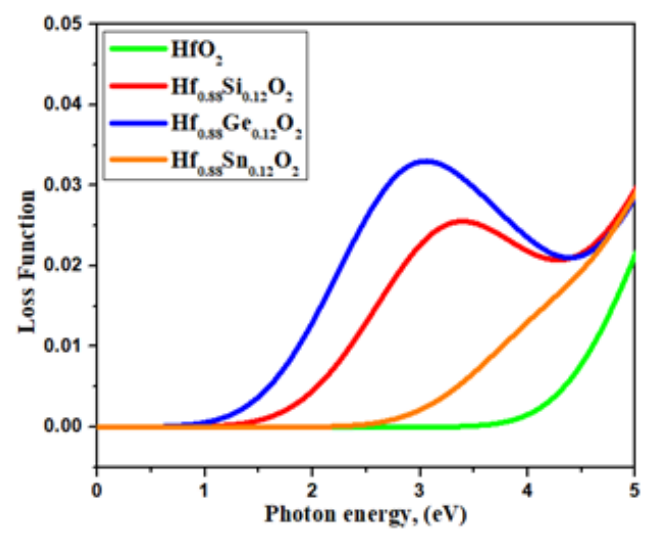

\section{Figure 9}

Loss Function

\section{Figure 10}

a) Molecular electrostatic potential map for $\mathrm{HfO}_{2}$, b) Molecular electrostatic potential map for $\mathrm{Hf}_{0.88} \mathrm{Si}_{0.12} \mathrm{O}_{2}, \mathrm{c}$ ) Molecular electrostatic potential map for $\mathrm{Hf}_{0.88} \mathrm{Ge}_{0.12} \mathrm{O}_{2}$, and d) Molecular electrostatic potential map for $\mathrm{Hf}_{0.88} \mathrm{Sn}_{0.12} \mathrm{O}_{2}$.

\section{Supplementary Files}

This is a list of supplementary files associated with this preprint. Click to download.

- floatimage1.jpeg 